\title{
Therapy of Bicarbonate-losing Renal Tubular Acidosis
}

\author{
R. A. DONCKERWOLCKE, G. J. VAN STEKELENBURG, and H. A. TIDDENS \\ From the Wilhelmina Kinderziekenhuis, University Children's Hospital, Utrecht, Netherlands
}

Donckerwolcke, R. A., van Stekelenburg, G. J., and Tiddens, H. A. (1970). Archives of Disease in Childhood, 45, 774. The therapy of bicarbonate-losing renal tubular acidosis. A 2-year-old-girl with severe bicarbonate-losing renal tubular acidosis was treated successively with bicarbonate, THAM, and two diuretics, hydrochlorothiazide and frusemide. Only with hydrochlorothiazide was adequate correction of the acid-base balance achieved. The relative importance of changes induced by this treatment in the extracellular fluid volume and in chloride depletion was assessed.

In treating patients with bicarbonate-losing renal tubular acidosis, Rodriguez Soriano and co-workers $(1967 \mathrm{a}, \mathrm{b})$ studied bicarbonate medication and pointed out the necessity of raising the plasma $\left[\mathrm{HCO}_{3}^{-}\right]$to a normal level. Since in this condition the renal threshold for $\mathrm{HCO}_{3}^{-}$is lowered, this course ieads to bicarbonaturia. The bicarbonate depletion can be limited, and the total dose required thus reduced, by frequently administering small amounts; in this way Rodriguez Soriano et al. (1967 a, b) was able to achieve adequate correction in patients with only a slightly lowered $\mathrm{HCO}_{3}^{-}$threshold, but no patients with a substantially lowered threshold were studied. Rampini et al. (1968) used diuretics in treating the impaired bicarbonate reabsorption in a patient with the Toni-Debré-Fanconi syndrome. Three diuretics were tried, hydrochlorothiazide, frusemide, and triamterene, but only with hydrochlorothiazide was adequate correction of acid-base balance achieved. They were unable to explain the difference in effect.

This paper presents the results of treating a patient with renal acidosis using bicarbonate, tris-hydroxymethyl-amino-methane (THAM), and two different diuretics.

\section{Patient and Methods}

The study concerns a 2-year-old girl described in an accompanying paper (Donckerwolcke, van Stekelenburg, and Tiddens, 1970). She was weighed daily and measured three times per week, using methods recommended by Tanner, Whitehouse, and Takaishi (1966). The $p H$, $\mathrm{PCO}_{2}, \mathrm{HCO}_{3}^{-}$, and total $\mathrm{Co}_{2}$ values were determined in finger-prick blood by the Astrup method. Blood volume was determined with radioactive iodine $\left({ }^{131} \mathrm{I}\right)$ bound to human serum albumin. The bromide volume

Received 6 May 1970. was determined in addition. The two parameters were measured simultaneously (de Planque et al., 1965), using the Volémetron. The extracellular (ECF) volume could be calculated from bromide volume and blood volume.

Therapeutic methods. A low salt diet was given $(0.75 \mathrm{~g} . \mathrm{NaCl} / 24$ hours) throughout the period of treatment. The patient was treated successively with sodium bicarbonate, a $15 \%$ THAM solution buffered with citric acid to $p \mathrm{H} 8 \cdot 2$, and two different diuretics, hydrochlorothiazide and frusemide.

\section{Results}

Treatment with bicarbonate. Initially, treatment with citrate had to be discontinued because of gastro-intestinal upset; sodium bicarbonate medication was then started at a daily dosage of $3 \mathrm{~g}$., increased to $15 \mathrm{~g}$., administered in eight fractional doses distributed evenly over 24 hours. When the total daily dose reached $15 \mathrm{~g}$. $(22 \mathrm{mEq} / \mathrm{kg}$.), this medication also had to be abandoned because of gastro-intestinal symptoms. There was a negligible effect on serum $\mathrm{pH}, \mathrm{HCO}_{3}^{-}$, and electrolytes (Fig. 1).

Treatment with THAM. This compound was given orally in increasing doses up to 1.25 g./kg. per day divided into six doses. After three weeks it had to be discontinued because of severe diarrhoea. Only a slight effect on serum $p H$, $\mathrm{PCO}_{2}$, standard $\mathrm{HCO}_{3}^{-}$, and total $\mathrm{CO}_{2}$ was observed (Table I).

Treatment with two different diuretics. The optimal dosage was established empirically for both compounds. To prevent hyponatraemia, salt was added to the low sodium diet, first in the form 
TABLE I

Effect of Oral Treatment with THAM

\begin{tabular}{|c|c|c|c|c|c|c|c|c|c|}
\hline \multicolumn{2}{|c|}{ Date (September 1969) } & \multirow{2}{*}{$\begin{array}{c}1 \text { st } \\
7 \cdot 12 \\
25 \cdot 0 \\
9 \cdot 7 \\
8 \cdot 5\end{array}$} & \multirow{2}{*}{$\begin{array}{c}\text { 2nd } \\
7 \cdot 14 \\
26 \cdot 4 \\
10 \cdot 6 \\
9 \cdot 4\end{array}$} & \multirow[t]{2}{*}{$\rightarrow$} & \multirow{2}{*}{$\begin{array}{c}5 \text { th } \\
7 \cdot 17 \\
20 \cdot 4 \\
10 \cdot 6 \\
8 \cdot 0\end{array}$} & \multirow[t]{2}{*}{$\rightarrow$} & \multirow{2}{*}{$\begin{array}{c}\text { 10th } \\
7 \cdot 19 \\
26 \cdot 5 \\
11 \cdot 2 \\
9 \cdot 1\end{array}$} & \multirow{2}{*}{$\rightarrow$} & \multirow{2}{*}{$\begin{array}{l}17 \text { th } \\
7 \cdot 16 \\
30 \\
11 \cdot 8 \\
11 \cdot 2\end{array}$} \\
\hline Blood chemistry & $\begin{array}{l}p \mathrm{H} \\
\mathrm{PcO}_{2}(\mathrm{~mm} . \mathrm{Hg}) \\
\text { St. } \mathrm{HCO}_{3}^{-}(\mathrm{mEq} / \mathrm{l} .) \\
\text { Total } \mathrm{CO}_{2}(\mathrm{mEq} / \mathrm{l} .)\end{array}$ & & & & & & & & \\
\hline Treatment & THAM (g./kg. per day) & 0 & 0.5 & & 0.75 & & 1 & & $1 \cdot 25$ \\
\hline
\end{tabular}

of $\mathrm{NaCl}\left(1.5 \mathrm{~g}\right.$. daily) and then as $\mathrm{NaHCO}_{3}(3 \mathrm{~g}$. daily). The effects of the two diuretics are shown in Fig. 2 and 3. Hydrochlorothiazide led to a good correction of the serum $p \mathrm{H}$ and $\mathrm{HCO}_{3}^{-}$but was accompanied by severe hypopotassaemia, such that substantial amounts of $\mathrm{KHCO}_{3}$ (up to $10 \mathrm{~g}$. daily) had to be added to the therapy.

The initial effective dose of hydrochlorothiazide was $20 \mathrm{mg}$. daily; once correction was achieved, this could be reduced to $10 \mathrm{mg}$. daily (distributed over the day in four doses). No complications occurred during five months of this medication, though plasma potassium remained very low in spite of ingesting large amounts of $\mathrm{KHCO}_{3}$. No associated ECG changes were observed. By contrast, with frusemide no clear effect was obtained though the daily dosage was increased to $30 \mathrm{mg}$. (Fig. 3).

\section{Discussion}

Treatment with bicarbonate. On theoretical grounds it would be predicted that, taking into account the GFR $\left(27 \mathrm{mg}\right.$. $/ \mathrm{min}$. per $\left.0.3 \mathrm{~m} .{ }^{2}\right)$ and the $\mathrm{HCO}_{3}^{-}$threshold $(10.5 \mathrm{mEq} / 1$.$) , a daily dose of$ $375 \mathrm{mEq}$ or $31.5 \mathrm{~g} . \mathrm{NaHCO}_{3}$ would have had to be administered to attain a constant serum level of $24 \mathrm{mEq} / \mathrm{l}$. So large an amount of sodium bicarbonate as is thus required by patients with a very low bicarbonate threshold and low $\mathrm{HCO}_{3}^{-}$reabsorption cannot be administered orally; hence this mode of

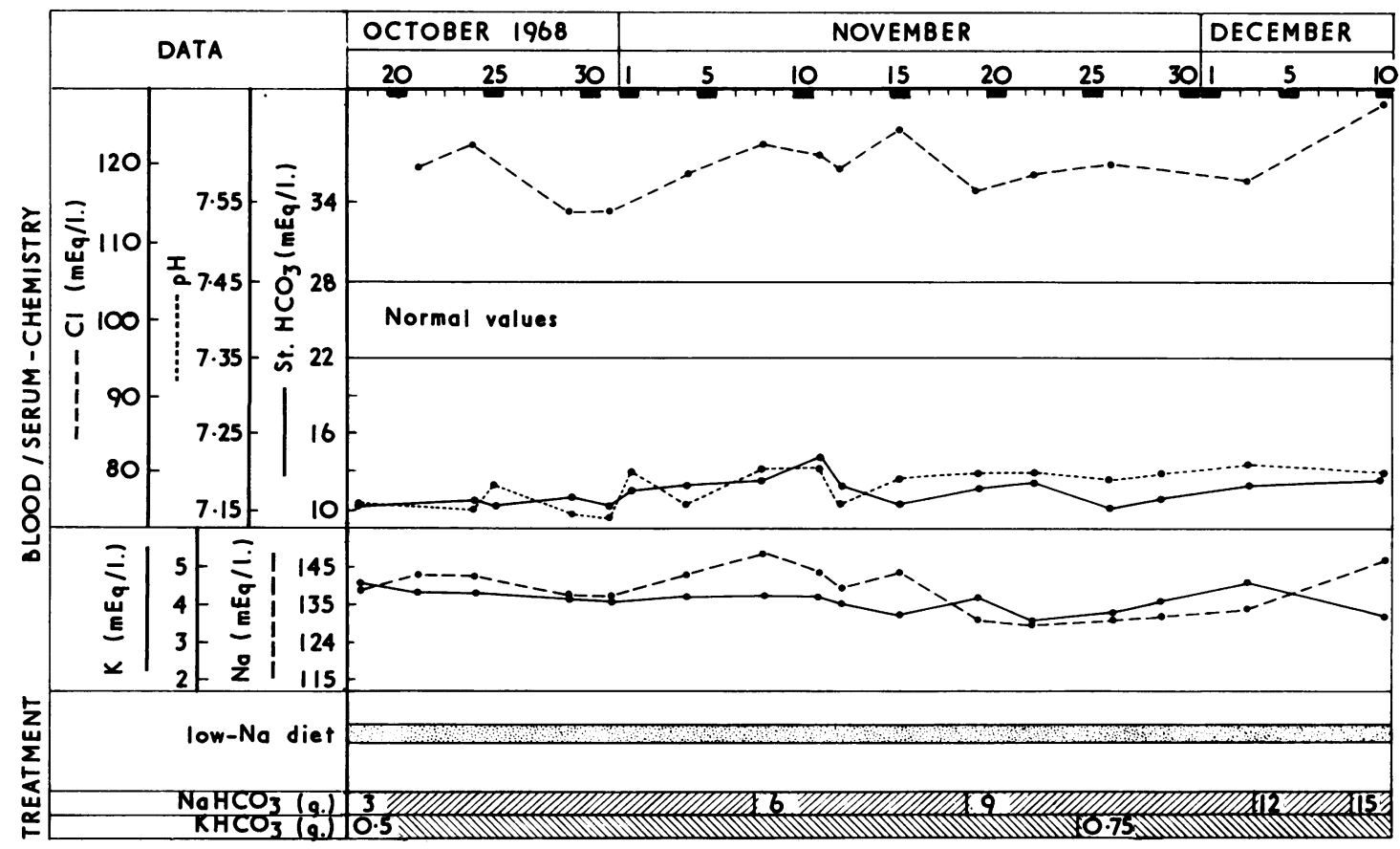

FIG. 1.-Serum acid-base and electrolyte values during treatment with sodium bicarbonate. 


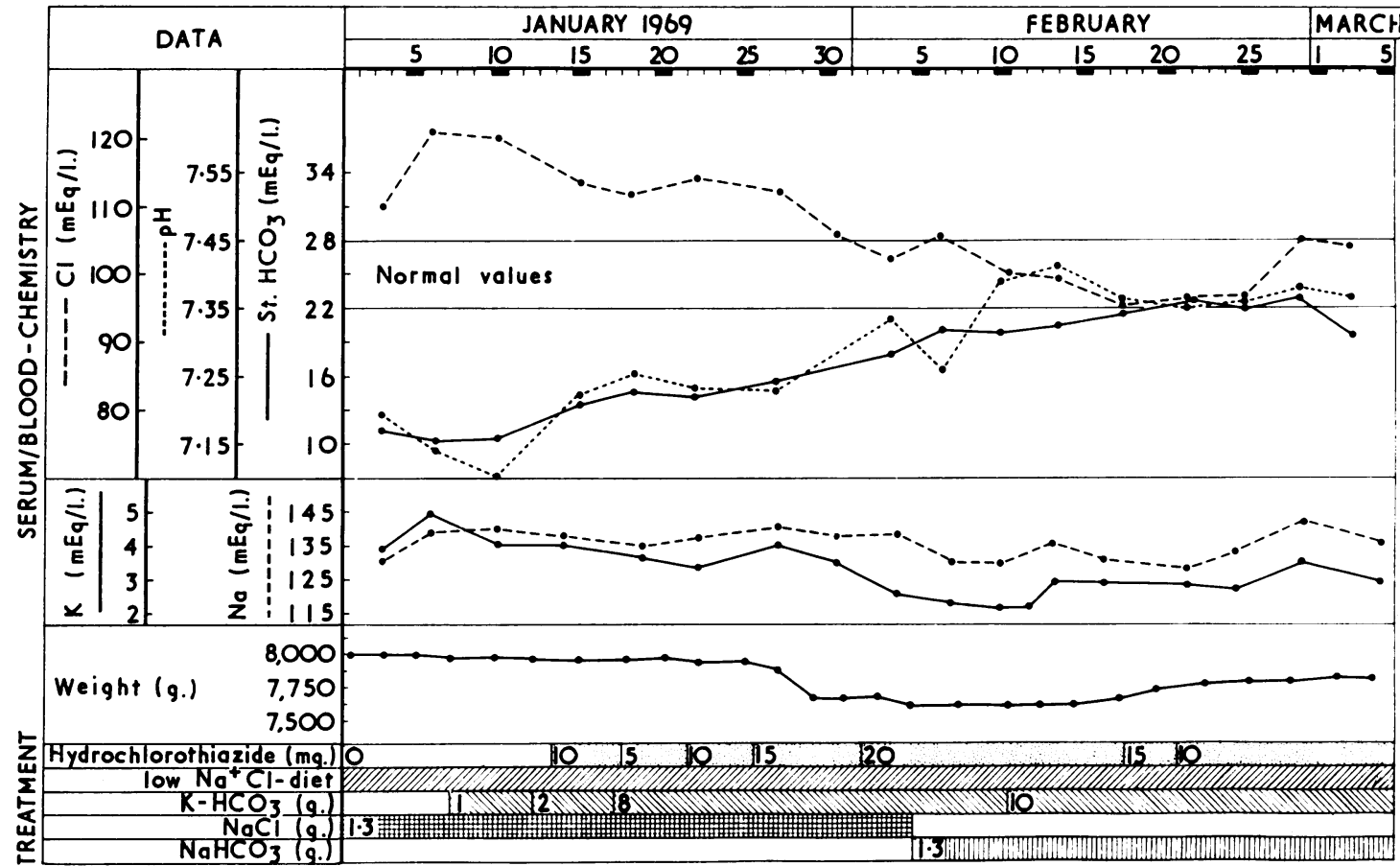

FIG. 2.-Serum acid-base and electrolyte values during treatment with hydrochlorothiazide.

treatment is practicable only in patients with a minor lowering of the threshold.

Treatment with THAM. Vert et al. (1968) administered THAM to patients with severe acidosis resulting from various renal affections, with a favourable effect in a patient with distal tubular acidosis (type Lightwood).

The failure of this therapy in our patient, with pronounced proximal tubular acidosis, can be explained as follows. Administration of THAM reduces $\left[\mathrm{H}^{+}\right]$and thus leads to a change in the relative concentration of all proton donor and proton acceptor pairs operating as tuffer systems in the biological $p H$ range (Strauss, 1968). For the $\mathrm{HCO}_{3}^{-} / \mathrm{H}_{2} \mathrm{CO}_{3}$ buffer system, this implies a decrease in $\left[\mathrm{H}_{2} \mathrm{CO}_{3}\right]$ and an increase in $\left[\mathrm{HCO}_{3}^{-}\right]$. In our patient an increase in serum $\left[\mathrm{HCO}_{3}^{-}\right]$led to increased excretion, which greatly reduced the effect. Thus this therapy also seems to be of little value in patients with a severely lowered bicarbonate threshold.

Treatment with diuretics. Only with hydrochlorothiazide did we achieve correction of the acidbase balance; frusemide at the dosage used ( $3 \mathrm{mg}$./ kg.) was ineffective. These findings corroborate Rampini's observations.

Diuretics can cause an increase in bicarbonate reabsorption by three different mechanisms of action: (1) by reduction of the extracellular volume; (2) by causing $\mathrm{Cl}^{-}$depletion; and (3) by increased $\mathrm{K}+$ excretion, resulting in intracellular $\mathrm{K}+$ depletion. Several investigators have studied these various factors. The effect of changes in extracellular volume on renal $\mathrm{HCO}_{3}^{-}$reabsorption was studied by Kunau et al. (1966), who demonstrated that expansion of the extracellular volume reduced $\mathrm{HCO}_{3}^{-}$reabsorption in the proximal tubule. Oetliker and Rossi (1969) demonstrated in two patients with Lowe's syndrome that the renal $\mathrm{HCO}_{3}^{-}$ threshold was directly dependent on the plasma volume. Reduction of the extracellular volume gives rise to increased sodium avidity, whereupon sodium reabsorption increases due to raised $\mathrm{Na}+/ \mathrm{H}+$ exchange, resulting in increased $\mathrm{HCO}_{3}^{-}$reabsorption. The specific effect of chloride on the acid-base balance was studied by Schwartz et al. (1961), Gulyassy, van Ypersele de Strihou, and Schwartz (1962), and Needle, Kaloyanides, and Schwartz (1964), who showed that selective depletion of the chloride reserves led to metabolic alkalosis, that this 


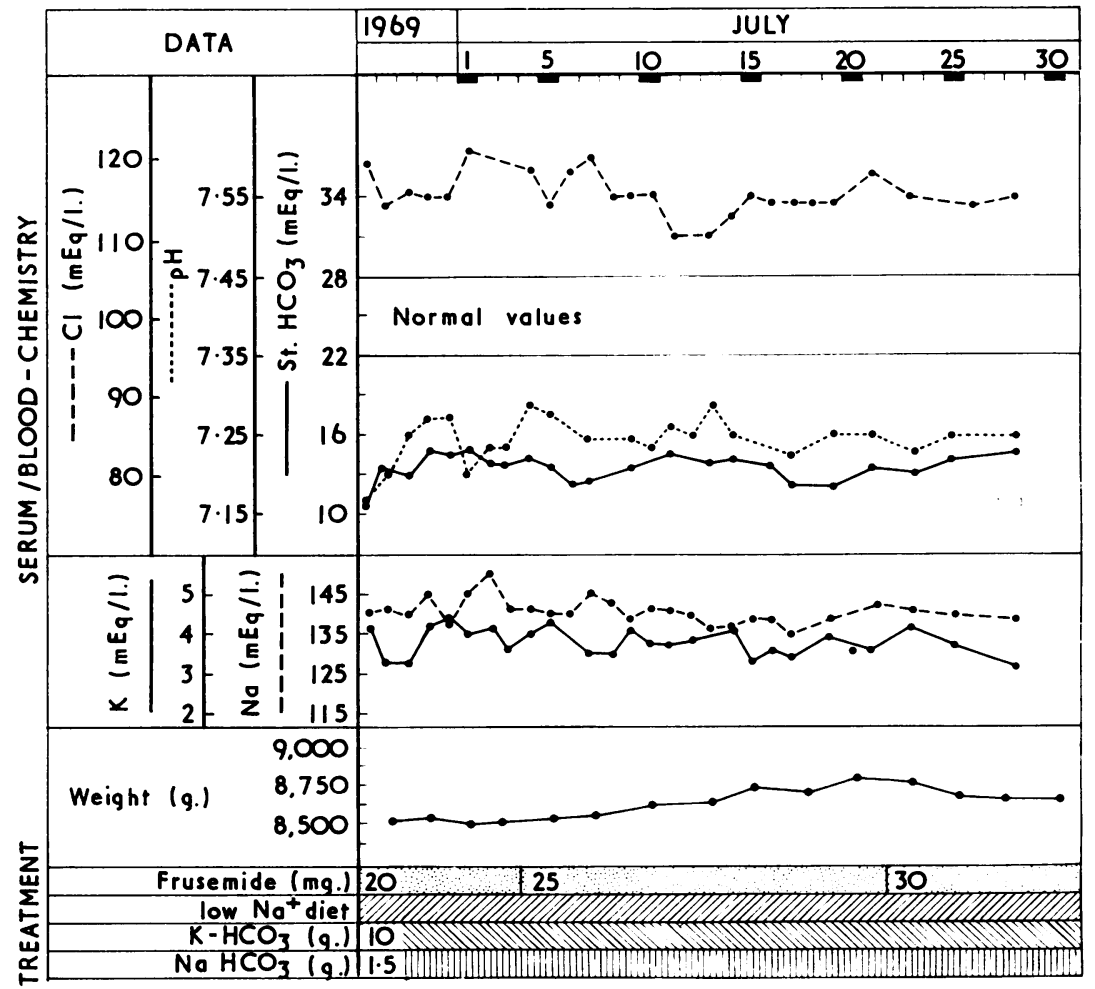

FIG. 3.-Serum acid-base and electrolyte values during treatment with frusemide.

alkalosis was maintained by chloride restriction in the diet, and that chloride administration was essential in restoring the acid-base balance to normal. However, these conditions of chloride depletion are associated with a reduction of the extracellular volume (Seldin and Wilson, 1966), and the resulting raised $\mathrm{Na}+/ \mathrm{H}+$ exchange can explain the alkalosis. Cohen (1968) suggested that, in alkalosis induced by diuretics, the restoration of the acidbase balance was achieved by restoration of the extracellular volume and chloride repletion, and that these two factors were interdependent. Though
Rector, Bloomer, and Seldin (1964) have indicated that in hypopotassaemia the proximal reabsorption of $\mathrm{HCO}_{3}^{-}$increases, the hypopotassaemia in his experimental arrangement was explicable as a result of increased $\mathrm{Na}+/$ cation exchange (Schwartz, van Ypersele de Strihou, and Kassirer, 1968).

Our study has shown that, during treatment with diuretics at the dosage used (by us and by Rampini et al., 1968), the extracellular volume and blood volumes decrease only during hydrochlorothiazide medication (Table II).

In addition we determined the relative importance

TABLE II

Extracellular Fluid Volume during Treatment with Diuretics

Extracellular Fluid Volume Measurements

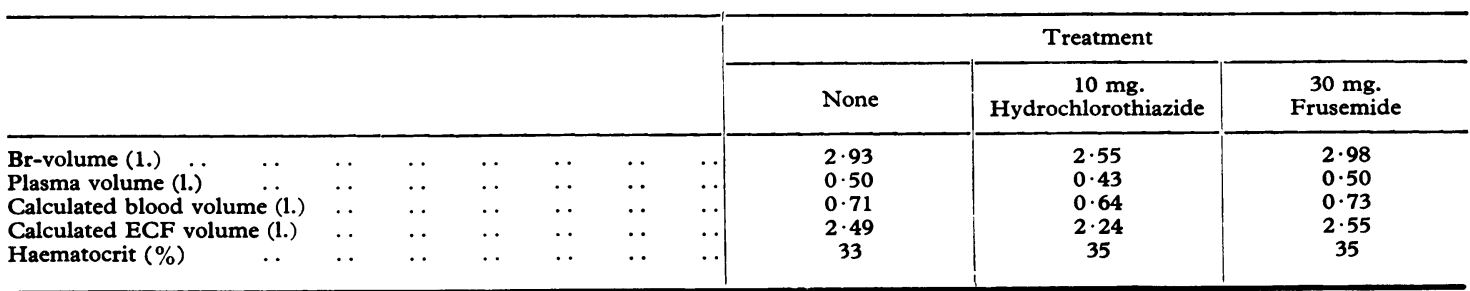




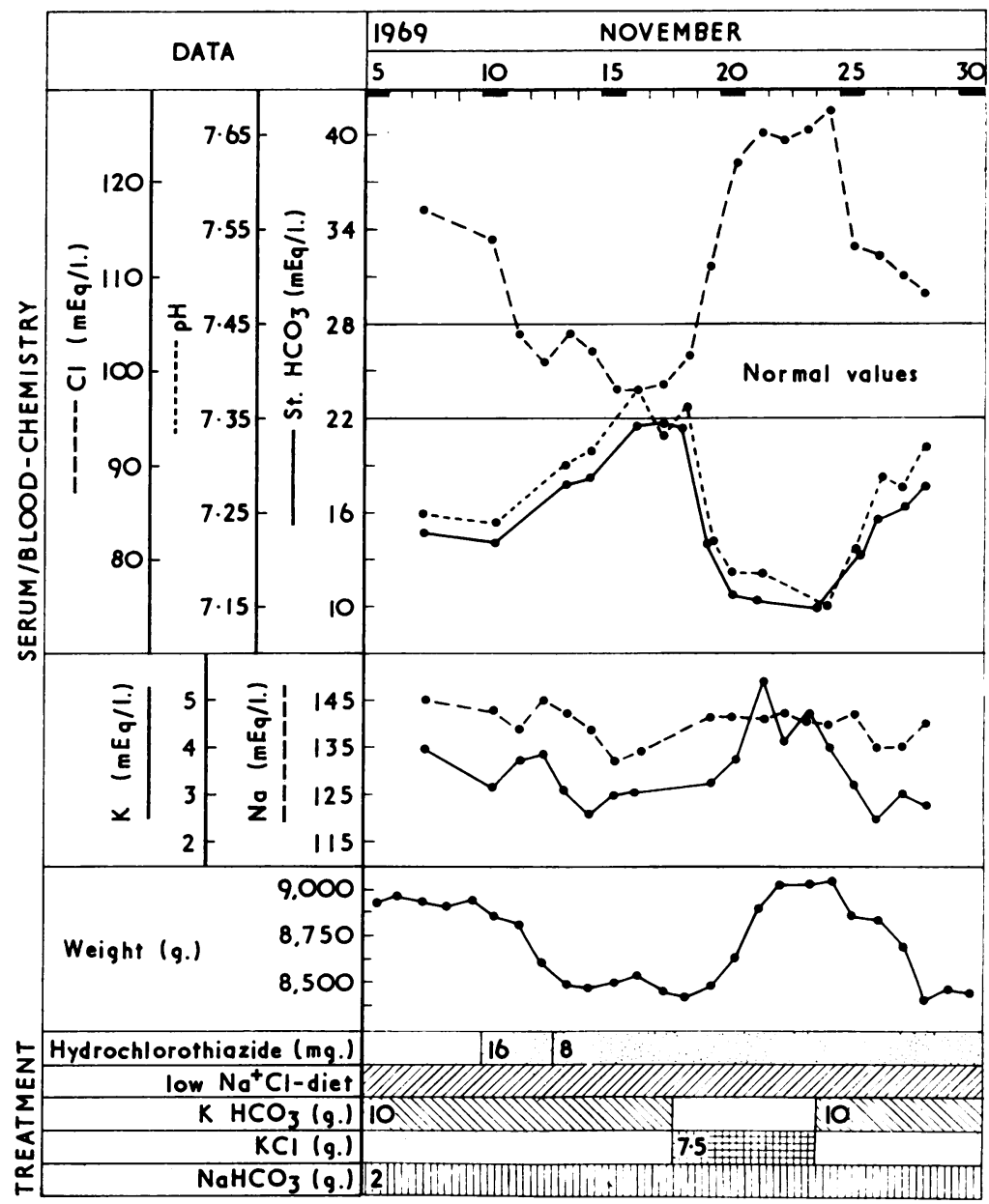

FiG. 4.-Effect of giving chloride (as $\mathrm{KCl}$, orally) on serum acid-base and electrolyte values and on bodyweight during treatment with hydrochlorothiazide.

of chloride deficiency, during a situation of increased $\mathrm{HCO}_{3}^{-}$reabsorption and reduced extracellular volume. To a regimen consisting of a low-sodium (88 mg./day), low-chloride (232 mg./day) diet, with a daily administration of $8 \mathrm{mg}$. hydrochlorothiazide and $2 \mathrm{~g}$. $\mathrm{NaHCO}_{3}$, potassium $(100 \mathrm{mEq})$ in the form either of $\mathrm{KHCO}_{3}$ or of $\mathrm{KCl}$ was added successively. The effect of chloride on the acid-base balance and on the extracellular volume (measured by changes in body weight) was thereby studied.

Addition of chloride led to recurrence of acidosis and to expansion of the extracellular volume (Fig. 4). Rampini et al., 1968 has shown that substituting potassium phosphate for potassium citrate in the course of treatment with hydrochlorothiazide did not alter the acid-base balance, so that the recurrence of acidosis in our patient was unlikely to have been the result of the withdrawal of bicarbonate.

These findings corroborate Cohen's (1968) contention that chloride depletion and reduction of the extracellular volume are interdependent.

\section{Conclusions}

Severe forms of bicarbonate-losing renal tubular acidosis cannot be corrected by means of oral sodium bicarbonate or buffer solutions owing to the low threshold for and consequent losses of $\mathrm{HCO}_{3}^{-}$. 
Diuretic medication is a good alternative in these conditions, with a diuretic that exerts its influence mainly on the distal nephron. The resulting rise in proximal $\mathrm{Na}+/ \mathrm{H}+$ exchange can lead to restoration of the acid-base balance.

With a diuretic-induced augmentation of $\mathrm{Na}+1$ cation exchange, chloride depletion and extracellular volume are closely correlated. Consequently, attempts to correct hypopotassaemia and alkalosis by giving potassium chloride (Schwartz et al., 1968) may prove ineffective. Correction of changes in the acid-base balance in our experiments also led to a diminution of the effect of the diuretic on extracellular volume.

\section{REFERENCES}

Cohen, J. J. (1968). Correction of metabolic alkalosis by the kidney after isometric expansion of extracellular fluid. Fournal of Clinical Investigation, 47, 1181.

Donckerwolcke, R. A., van Stekelenburg, G. J., and Tiddens, H. A. (1970). A case of bicarbonate-losing renal tubular acidosis with defective carboanhydrase activity. Archives of Disease in Childhood, 45, 769.

Gulyassy, P. F., van Ypersele de Strihou, C., and Schwartz, W. B. (1962). On the mechanism of nitrate-induced alkalosis. The possible role of elective chloride depletion in acid-base regulation. Fournal of Clinical Investigation, 41, 1850.

Kunau, R., Frick, A., Rector, F. C., Jr., and Seldin, D. W. (1966). Effect of extracellular fluid (E.C.F.) volume expansion, $K+$ deficiency and $\mathrm{pCO}_{2}$ on bicarbonate reabsorption in the rat kidney. Clinical Research, 14, 380.

Needle, M. A., Kaloyanides, G. J., and Schwartz, W. B. (1964). The effects of selective depletion of hydrochloric acid on acidbase and electrolyte equilibrium. Fournal of Clinical Investigation, 43, 1836.

Oetliker, O., and Rossi, E. (1969). The influence of extracellularfluid volume on the renal bicarbonate threshold. A study of two children with Lowe's syndrome. Pediatric Research, 3, 140. de Planque, B. A., Geyskes, C. G., van Dongen, R., and Dorhout Mees, E. J. (1965). Simultaneous determination of extracellular volume and blood volume with the volemetron. Clinica Chemica Acta, 11, 270.

Rampini, S., Fanconi, A., Illig, R., and Prader, A. (1968). Effect of hydrochlorothiazide on proximal renal tubular acidosis in a patient with idiopathic "de Toni-Debré-Fanconi syndrome". Helvetica Paediatrica Acta., 23, 3.

Rector, F. C. Jr., Bloomer, H. A., and Seldin, D. W. (1964). Effect of potassium deficiency on the reabsorption of bicarbonate in the proximal tubule of the rat kidney. Fournal of Clinical Investigation, 43, 1976.

Rodriguez Soriano, J., Boichis, H., and Edelmann, C. M. Jr. (1967a). Bicarbonate reabsorption and hydrogen ion excretion in children with renal tubular acidosis. Fournal of Pediatrics, 71, 802 .

-, Stark, H., and Edelmann, C. M. (1967b). Proximal renal tubular acidosis. A defect in bicarbonate reabsorption with normal urinary acidification. Pediatric Research 1, 81.

Schwartz, W. B., Hays, R. M., Polak, A., and Haynie, G. D. (1961). Effects of chronic hypercapnia on electrolyte and acid-base equilibrium. II. Recovery, with special reference to the influence of chloride intake. Fournal of Clinical Investigation, 40, 1238.

_- van Ypersele de Strihou, C., and Kassirer, J. P. (1968). Role of anions in metabolic alkalosis and potassium deficiency. New England fournal of Medicine, 279, 630.

Seldin, D. W., and Wilson, J. D. (1966). Renal tubular acidosis. In The Metabolic Basis of Inherited Diseases, by Standbury, J. B., Wyngaarden, J. B., and Fredrickson, D. S. p. 1230, 2nd ed. McGraw-Hill, New York.

Strauss, J. (1968). Tris (hydroxymethyl) amino-methane (THAM): A pediatric evaluation. Pediatrics, 41, 667.

Tanner, J. M., Whitehouse, R. M., and Takaishi, M. (1966). Standards from birth to maturity for height, weight, height velocity and weight velocity: British children, 1965. Archives of Disease in Childhood, 41, 454 and 613.

Vert, P., Marchal, C., Neimann, N., and Pierson, M. (1968). Traitement symptomatique des acidoses rénales par administration orale de citrate de THAM. Archives Françaises de Pédiatrie, 25, 91.

Correspondence to Professor H. A. Tiddens, Wilhelmina Kinderziekenhuis, University Children's Hospital, Utrecht, Netherlands. 